\title{
Flexible zinc oxide photoelectrode for photo electrochemical energy conversion
}

\author{
T. Shiyani ${ }^{1}$, I. Banerjee ${ }^{1}$, Santosh K. Mahapatra ${ }^{2}$, and Asim K. Ray ${ }^{3, *}$ (1) \\ ${ }^{1}$ School of Nanosciences, Central University of Gujarat, Gandhinagar 382030, Gujarat, India \\ ${ }^{2}$ School of Physical Sciences, Central University of Punjab, Bathinda 151001, Punjab, India \\ ${ }^{3}$ Brunel University, Uxbridge, London, UK
}

Received: 16 March 2021

Accepted: 28 April 2021

Published online:

18 May 2021

(C) This is a U.S. government work and not under copyright protection in the U.S.; foreign copyright protection may apply 2021

\begin{abstract}
Photoelectrochemical properties have been investigated for flexible photoelectrodes containing $310 \mathrm{~nm}$ thick $\mathrm{ZnO}$ film on spin-coated ITO/PET. The high crystalline structure of $\mathrm{ZnO}$ was studied using x-ray diffraction pattern. A value of $3.4 \mathrm{eV}$ has been estimated for optical band gap from its absorption spectra. The flexible $\mathrm{ZnO}$ photoelectrode was demonstrated to generate photoelectrochemical current. The photocurrents are enhanced by $4 \%$ whereas flat-band potential is shifted by $8 \mathrm{~V}$ due to the illumination. Values of 1.022 and 0.714 $\mathrm{AW}^{-1}$ were found to be for photo switching and photoresponsivity, respectively. $\mathrm{ZnO} / \mathrm{ITO} / \mathrm{PET}$ can be used as a substrate for making flexible hybrid PEC devices to generate solar power and solar fuels.
\end{abstract}

\section{Introduction}

Photoelectrochemical (PEC) cells are one type of solar cells that include photoelectrodes and electrolyte [1]. Photoelectrodes can be fabricated from various materials including organic and inorganic materials. The materials of photoelectrodes decide the performance of PECs [2]. Semiconducting photoelectrodes are mostly used in PECs for conversion of photons into electron-hole pairs [3]. First PEC was demonstrated using $\mathrm{TiO}_{2}$. Thereafter, many nanostructured metal oxides have been used in PECs because the advantages of high surface to volume ratio in nanomaterials [4].

Zinc oxide $(\mathrm{ZnO})$ is a n-type semiconducting material with a wide direct energy band gap with a value of $3.37 \mathrm{eV}$ at room temperature [5]. Values of $3.96 \times 10^{20} \mathrm{~cm}^{-3}$ and $17.7 \mathrm{~cm}^{2} \mathrm{~V}^{-1} \mathrm{~s}^{-1}$ have been reported for electron concentration and mobility of co-doped RF sputtered ZnO films. Optical transmission value is similar to $85-90 \%$ in the range 400-700 nm for these films [6]. Because of its low toxicity and high electronic conductivity, it has been extensively studied for exploring applications in optoelectronics as solar cells, gas sensors, varistors and a phosphor for colour displays [7]. The On-Off ratio as high as $2.2 \times 10^{4}$ has been reported for the $\mathrm{ZnO}$ memristor in a sandwich configuration with sputtered gold top electrode [8].

Flexible photo-electrochemical cells of $\mathrm{ZnO}$ on indium tin oxide (ITO) coated polyethylene terephthalate (PET) substrates, incorporating muga silk

Address correspondence to E-mail: asim.ray@brunel.ac.uk 
nanoparticles of sizes ranging between $28 \mathrm{~nm} \mathrm{-}$ $142 \mathrm{~nm}$ have been recently studied under white light illumination of power $56 \mathrm{mWcm}^{-2}$. The value of photoresponsivity is found to be $0.119 \mu \mathrm{AW}^{-1}$. The rise time is $0.9 \mathrm{~s}$ while the corresponding decay time is $0.6 \mathrm{~s}$ [9]. Similarly configured photo-electrochemical cells using basil sensitized $\mathrm{ZnO}$ show $0.45 \%$ energy conversion efficiency. The photocurrent and photovoltage were enhanced by $1.33 \mathrm{nA}$ and $3 \mathrm{mV}$, respectively. Values of 1.3 and $0.024 \mu \mathrm{A} / \mathrm{W}$ have been reported for On-Off ratio and photoresponsivity, respectively [10]. Flexible Ultraviolet zinc nanorods photodetectors are reported to show photoresponsivity within the range of $0.13-0.19 \mathrm{~A} / \mathrm{W}$ under UV power density varying between 0.8 and 12.47 $\mathrm{mWcm}^{-2}$ [11]. ZnO films drop-cast on fluorine doped ITO substrates was coated with a layer of natural dye for hybrid photoelectrodes with improved performance [12]. The dye-sensitised solar cells have been fabricated using natural dye extracted from basil or ocimum leaves. These may also be used as photoelectrochemical cell for the applications of water splitting [13]. This article presents the photochemical properties of $310 \mathrm{~nm}$ thick spin coated $\mathrm{ZnO}$ films using commercially available nanoparticles.

\section{Experimental details}

\subsection{Materials and device fabrication}

$\mathrm{ZnO}$ thin films were deposited on ITO coated PET substrates (purchased from Sigma Aldrich) with prior cleaning through spin coating technique. Small volume of 40 weight $\%$ dispersion of $\mathrm{ZnO}$ nanoparticles $(130 \mathrm{~nm})$ dispersed in ethanol was spin coated on ITO/PET substrate at $250 \mathrm{rpm}$ and $2000 \mathrm{rpm}$ in a sequence for $15 \mathrm{~s}$ and $60 \mathrm{~s}$ respectively. The samples were kept for oven drying at $60{ }^{\circ} \mathrm{C}$ for $15 \min [14,15]$.

\subsection{Characteriation techniques}

X-Ray diffraction (XRD) patterns were acquired using a Bruker D8 Advance scanning in the $2 \theta$ range of 5-1001, with a step size of 0.021 per second using $\mathrm{CuK} \alpha$ radiation of wavelength $0.15406 \mathrm{~nm}$. ITO coated PET substrate was used for the UV-Visible. The absorption and transmittance spectra were recorded using UV-Visible spectrophotometer (Shimadzu 6120, Japan). The photoelectrochemical (PEC) measurements were performed in a standard three electrode configuration using Scanning electrochemical microscopy (SECM, CH Instrument, model CHI920D) as shown in Fig. 1. ZnO film was used as working electrode, a saturated calomel electrode (SCE) was used as reference and a Pt wire was used as counter electrode in a standard three electrode system with $0.1 \mathrm{M} \mathrm{Na}_{2} \mathrm{SO}_{4}$ aqueous solution as electrolyte. The fabricated $\mathrm{ZnO} / \mathrm{ITO} / \mathrm{PET}$ device was converted into photoelectrode and used as working electrode in PEC cell. The linear sweep voltametry technique was used at scan rate of $0.1 \mathrm{~V} / \mathrm{s}$. The white LED light (with intensity of about $56 \mathrm{~mW} / \mathrm{cm}^{2}$ ) was used as light source to measure current-voltage (I-V) behavior of the PEC cell under dark and light $[16,17]$.

\section{Result and Discussion}

\subsection{Structural properties of $\mathrm{ZnO} / \mathrm{ITO}$ thin film}

XRD pattern of $\mathrm{ZnO}$ thin film grown on ITO-PET substrate is shown in Fig. 2. XRD experiments were performed with X-ray diffractometer. XRD pattern was used to study the orientation and phase of the sample. The marked diffraction peaks are corresponding to $\mathrm{ZnO}$. The (101) peak at $2 \theta=33.58^{\circ}$ was observed, which corresponds $\mathrm{ZnO}$ (JCPDS card No.

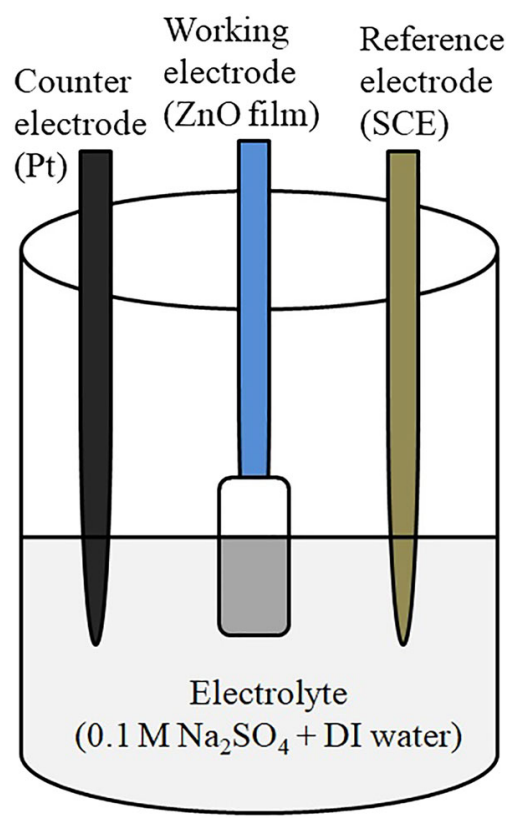

Fig. 1 Schematic representation of three electrode electrochemical system 
89-1397) corresponding to the hexagonal wurtzite structure of $\mathrm{ZnO}$. The two diffraction peaks at $47^{\circ}$ and $54.6^{\circ}$ that are corresponding to the ITO-PET substrate. The XRD pattern confirms $\mathrm{ZnO}$ film with high crystallinity.

\subsection{Optical properties}

The absorption spectra of $\mathrm{ZnO}$ thin film deposited on ITO coated PET substrate were measured by the UVVisible spectrometer in the wavelength range 200-1100 nm as shown in Fig. 3a. The absorption curve shows the absorption peak about $387 \mathrm{~nm}$ for $\mathrm{ZnO}$ thin film. The optical band gap of the films was determined using the Tauc plot as shown in Fig. $3 \mathrm{~b}$. The obtained band gap was found about $3.4 \mathrm{eV}$ for the $\mathrm{ZnO}$ thin film. The various optical parameters of $\mathrm{ZnO} / \mathrm{ITO} / \mathrm{PET}$ device are summarized in Table 1. The transmittance of the film was very high due to transparent behavior of film as shown in Fig. 3c. The Urbach curve is shown in Fig. 3d and Urbach energy is found at $0.2890 \mathrm{eV}$.

\subsection{Refractive index calculation}

$\mathrm{ZnO}$ film exhibits good transparency in the visible and infrared region $(\sim 78 \%)$. The refractive index $(n)$ at different wavelengths was calculated using the envelope curve method in the transmission spectra [18]. The equation for refractive index is expressed as Eq. (1). Values of refractive index $\mathrm{n}$ for $\mathrm{ZnO}$ film are found to be 2.0506 and 2.0501 at $492 \mathrm{~nm}$ and $802 \mathrm{~nm}$ wavelengths, respectively from Eq. (1).

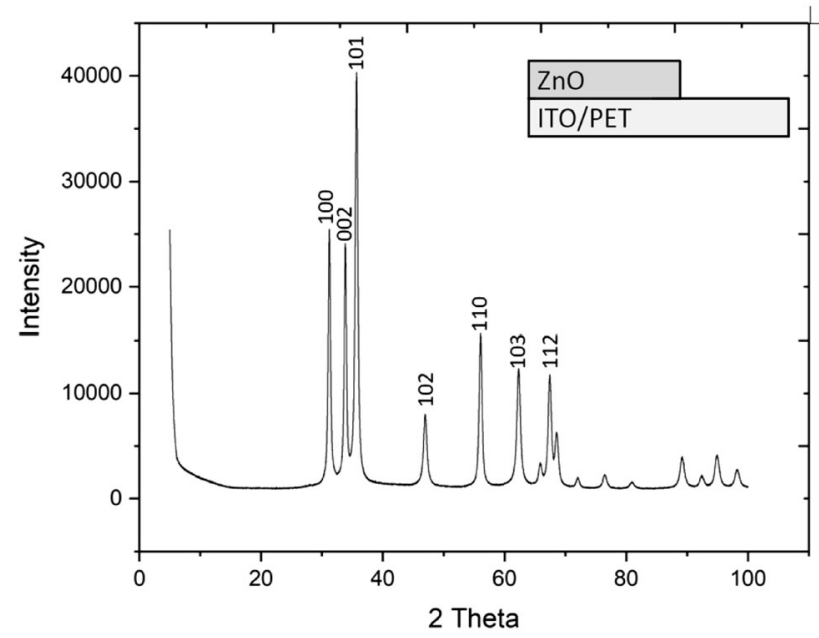

Fig. 2 X-ray diffraction patern of $\mathrm{ZnO} / \mathrm{ITO} / \mathrm{PET}$. The inset shows the device structure
$\mathrm{n}=\left[\mathrm{N}+\left(\mathrm{N}^{2}-\mathrm{n}_{\mathrm{s}}^{2}\right)^{1 / 2}\right]^{1 / 2}$

where $\mathrm{N}=2 \mathrm{~ns}\left[\left(\mathrm{~T}_{\mathrm{M}}-\mathrm{T}_{\mathrm{m}}\right) / \mathrm{T}_{\mathrm{M}} \mathrm{T}_{\mathrm{m}}\right]+\left(\mathrm{n}_{\mathrm{s}}^{2}+1\right) / 2$ and $\mathrm{n}_{\mathrm{s}}$ is refractive index of substrate. The values of refractive index are consistent with those reported recently [18].

\subsection{Thickness calculation}

The thickness of the $\mathrm{ZnO}$ film was calculated using the Eq. (2) [19]. The thickness of $\mathrm{ZnO}$ film was found as $310 \mathrm{~nm}$.

$t=\left(\lambda_{1} \lambda_{2}\right) /\left[2\left(\lambda_{1} n_{2}-\lambda_{2} n_{1}\right)\right]$

where $n_{1}$ and $n_{2}$ are the refractive indices corresponding to wavelengths $\lambda_{1}$ and $\lambda_{2}$, respectively.

\subsection{Urbach energy calculation}

The exponential dependence on the photon energy (hv) by the absorption coefficient $(\alpha)$ near the band edge for noncrystalline materials follows the Urbach relation as expressed in Eq. (3). Urbach curve shows the variation in the logarithm of the absorption coefficient as a function of the photon energy for $\mathrm{ZnO}$ film. The value of Urbach energy $(E u)$ is normally calculated by considering the reciprocal of the slope of the linear portion in the lower photon energy region of these curves [20]. The calculated values of Urbach energy for $\mathrm{ZnO}$ film is about $0.2890 \mathrm{eV}$.

$\alpha(v)=\alpha_{0} \exp \left(h v / E_{u}\right)$

where $\alpha_{0}$ is a constant, $E u$ is an energy which is interpreted as the width of the tail of localized states in the forbidden band gap, $v$ is the frequency of radiation, and $h$ is Planck's constant. The value of $0.2890 \mathrm{eV}$ for Urbach energy is believed to be relative to the degree of crystallinity in the spin-coated $\mathrm{ZnO}$ [21]

Values of optical parameters in Table 1 are consistent with published data [22]

\subsection{Photoelectrochemical properties}

The energy band diagram of $\mathrm{ZnO} / \mathrm{ITO} / \mathrm{PET}$ is shown in Fig. 4, which explains the charge transfer mechanism in PEC device. The photo electrochemical (PEC) response of the $\mathrm{ZnO} / \mathrm{ITO} / \mathrm{PET}$ with $\mathrm{Na}_{2} \mathrm{SO}_{4}$ electrolyte was recorded using linear sweep photovoltammogram and photoamperometric technique as 

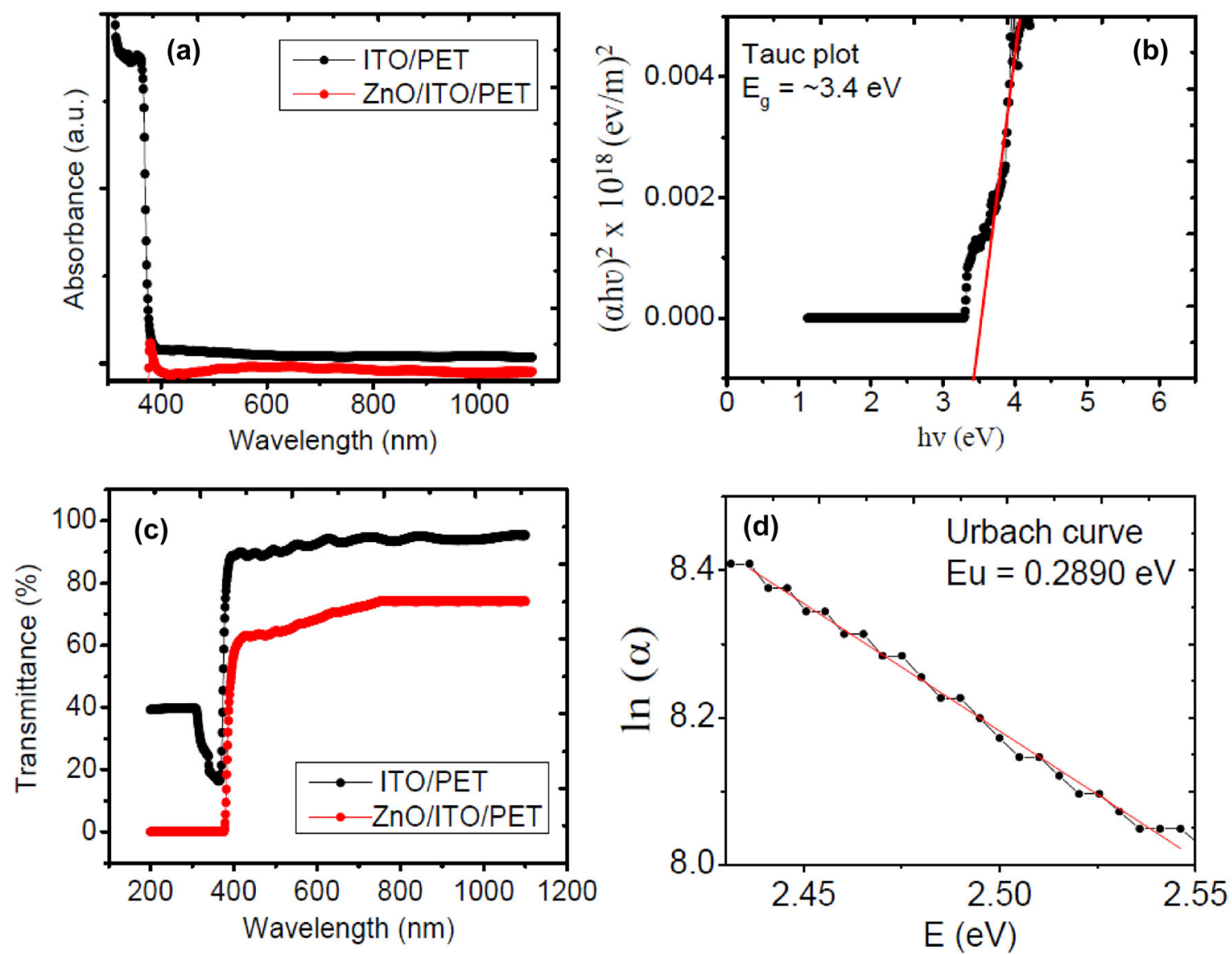

Fig. 3 a Absorbance spectra, b Tauc plot $\mathbf{c}$ Transmittance spectra, d Urbach curve of ZnO/ITO/PET

Table 1 Optical parameters of $\mathrm{ZnO} / \mathrm{ITO} / \mathrm{PET}$

\begin{tabular}{lllll}
\hline Device & Band gap $(\mathrm{eV})$ & \multicolumn{2}{l}{ Refractive index $(n)$} & Urbach energy $\left(\mathrm{E}_{\mathrm{u}}\right) \mathrm{eV}$ \\
\cline { 3 - 4 } & & $n$ at $492 \mathrm{~nm}$ & $n$ at $802 \mathrm{~nm}$ & \\
\hline ZnO/ITO/PET & 3.4 & 2.0506 & 2.0501 & 0.2890 \\
\hline
\end{tabular}

shown in Fig. 5 and 6, respectively. The dark and red color is shown for without illumination and under illumination, respectively. The PEC response confirms that the film was photoactive film. A negative slope of $\mathrm{I}-\mathrm{V}$ shows the n-type semiconducting behavior of $\mathrm{ZnO}$. At high photon energy, the maximum photovoltage dimishes due to the limited penetration depth of $\mathrm{ZnO}$. Then excited electron enters into the $\mathrm{ZnO}$ region and diffuses at back contact. As a result, there is a generation of photocurrent and photo voltage. The photo generated carriers are collected due to the electric field present at the semiconductor-electrolyte interface. The photocurrent is directly dependent on the properties of semiconductor layer [23]

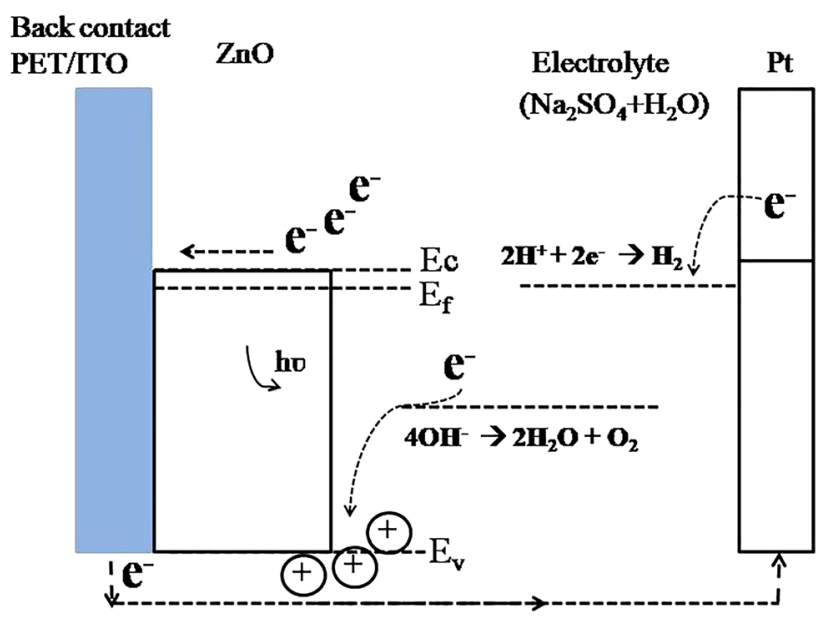

Fig. 4 A schematic of electron flow in photo electrochemical cell 
Fig. 5 Linear Sweep voltametry of $\mathrm{ZnO} / \mathrm{ITO} / \mathrm{PET}$ in dark (black) and light (red)

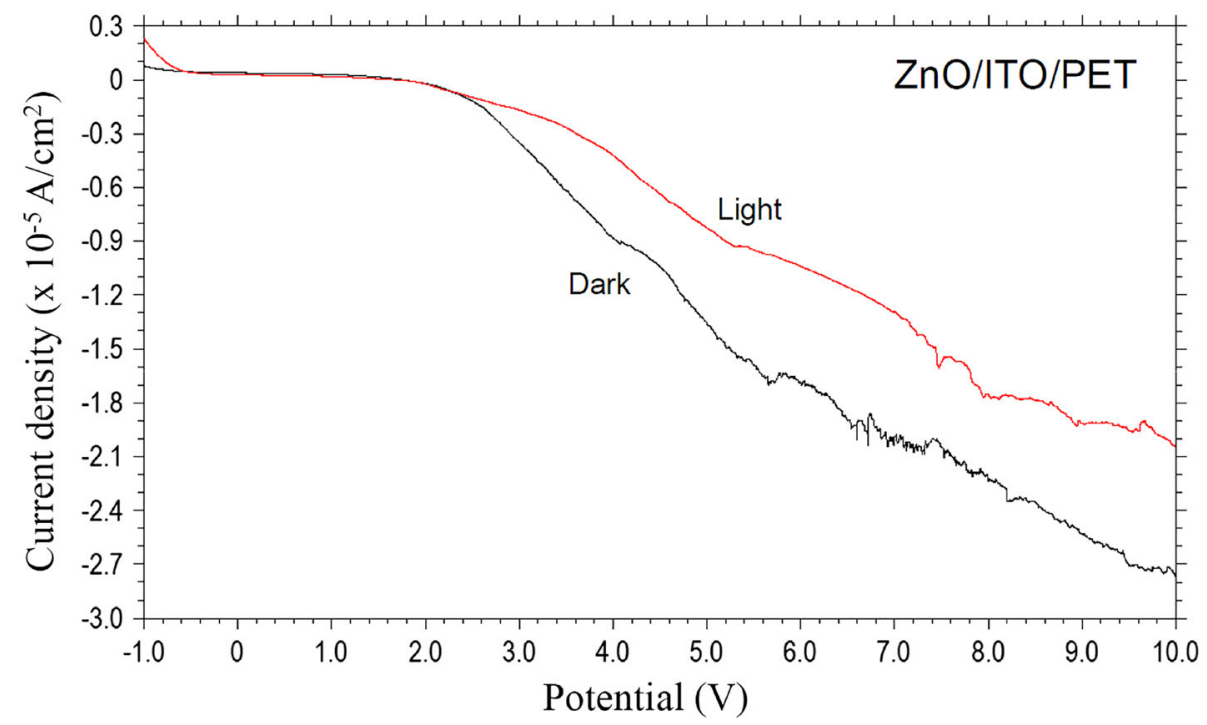

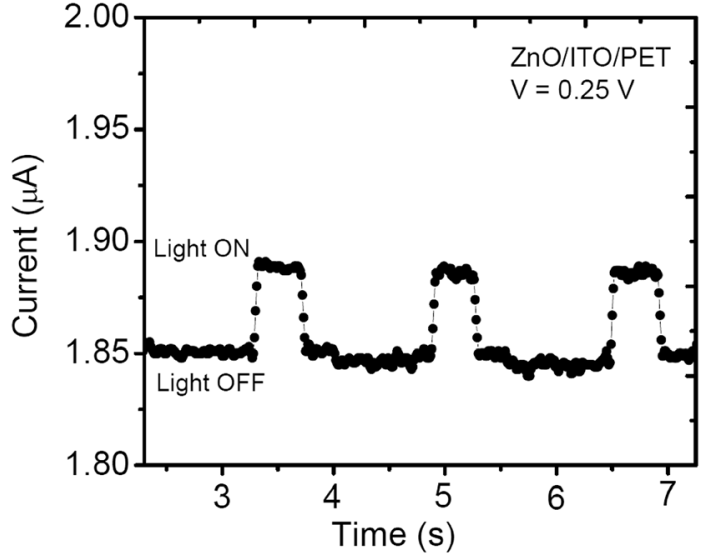

Fig. 6 Photoamperometric at $0.25 \mathrm{~V}$ of $\mathrm{ZnO} / \mathrm{PET}$

The I-V curves show the flat-band potential $\mathrm{V}_{\mathrm{FB}}$. It is the potential where there is no field in the semiconductor) shifts towards the negative values, which shows n-type behavior of semiconducting thin film in PEC device. The flat band potential was shifted towards higher value under illumination from $2.6 \mathrm{~V}$ to $3.4 \mathrm{~V}$. In the photoamperometric measurement, the working electrode is held at a constant $0.25 \mathrm{~V}$ potential and illuminated with white LED light for a short period of time. The photocurrent was observed at $1.85 \mu \mathrm{A}$ and $1.89 \mu \mathrm{A}$ for dark and illuminated condition, respectively. The photocurrent is enhanced by $4 \%$ and flat-band potential increased by $0.8 \mathrm{~V}$ due to the illumination. The flexible $\mathrm{ZnO}$ photoelectrode was demonstrated for photoswitching properties and photoresponsive behavior. The ON/OFF ratio and photoresponsivity were calculated about 1.0216 and
$0.7142 \mu \mathrm{A} / \mathrm{W}$, respectively. The measured photoelectrochemical parameters are summarized in Table 2.

$\mathrm{ZnO}$ can only absorb ultraviolet (UV) light (4\% in the sun light spectrum) due to its wide band gap [20]. Therefore, $\mathrm{ZnO}$ photoelectrodes can be modified with organic or inorganic materials to absorb visible and other spectrum of sun light. Biomaterials have high absorption in visible spectrum. Natural dyes can absorb the light in a wide range of wavelengths. Flexible $\mathrm{ZnO} / \mathrm{ITO} / \mathrm{PET}$ photoelectrodes can be used as a substrate for developing next generation hybrid solar energy conversion devices as well as wearable optoelectronic devices. [24].

\section{Conclusions}

We have demonstrated flexible $\mathrm{ZnO}$ photoelectrode for photoelectrochemical solar energy conversion. The flexible thin film solar cells have greater advantages for commercial productions because of their flexibility and lightweight features. Flexible $\mathrm{ZnO}$ PEC device has generated photocurrents of about $1.85 \mu \mathrm{A}$ and $1.89 \mu \mathrm{A}$ under dark and illumination, respectively. The flat band potential was shifted from 2.6 to $3.4 \mathrm{~V}$ due to the illumination. The photocurrents and flat-band potential are enhanced by $4 \%$ and $0.8 \mathrm{~V}$, respectively due to the illumination. The flexible $\mathrm{ZnO} / \mathrm{ITO} / \mathrm{PET}$ has shown photoswitching ON/OFF ratio and photoresponsivity about 1.0216 and 0.7142 $\mu \mathrm{A} / \mathrm{W}$, respectively. These results provide a fundamental understanding on flexible $\mathrm{ZnO}$ 
Table 2 Photoelectrochemical parameters for flexible $\mathrm{ZnO}$ photoelectrode

\begin{tabular}{|c|c|c|c|c|c|c|c|c|}
\hline \multirow[t]{2}{*}{ Device } & \multicolumn{2}{|c|}{ Photocurrent $(\mu \mathrm{A})$} & \multicolumn{2}{|c|}{$\mathrm{V}_{\mathrm{F}}(\mathrm{V})$} & \multicolumn{2}{|c|}{ Increment due to illumination } & \multirow[t]{2}{*}{ ON/OFF ratio $\left(\mathrm{I}_{\text {Light }} / \mathrm{I}_{\text {Dark }}\right)$} & \multirow[t]{2}{*}{ Photoresponsivity $\mathrm{R}\left(\mathrm{AW}^{-1}\right)$} \\
\hline & Dark & Light & Dark & Light & Photocurrent & $\mathrm{V}_{\mathrm{F}}(\mathrm{V})$ & & \\
\hline $\mathrm{ZnO} / \mathrm{ITO}$ & 1.85 & 1.89 & 2.6 & 3.4 & $4 \%$ & 0.8 & 1.0216 & $0.714 \mathrm{AW}^{-1}$ \\
\hline
\end{tabular}

photoelectrode and can be used to develop hybrid solar cells for generation of solar power as well as solar fuels.

\section{Acknowledgements}

The authors are thankful to Central Instrumentation Facility (CIF), Central University of Gujarat for providing scanning electrochemical microscope facility.

\section{Declarations}

Conflict of interest The authors declare no conflict of interest.

Open Access This article is licensed under a Creative Commons Attribution 4.0 International License, which permits use, sharing, adaptation, distribution and reproduction in any medium or format, as long as you give appropriate credit to the original author(s) and the source, provide a link to the Creative Commons licence, and indicate if changes were made. The images or other third party material in this article are included in the article's Creative Commons licence, unless indicated otherwise in a credit line to the material. If material is not included in the article's Creative Commons licence and your intended use is not permitted by statutory regulation or exceeds the permitted use, you will need to obtain permission directly from the copyright holder. To view a copy of this licence, visit http://creativecommons.org/licen ses/by $/ 4.0 /$.

\section{References}

1. R.N. Clayton, The earth and the sun. Science 332(6037), 1509-1510 (2011)

2. B. O'Regan, A low-cost, high-efficiency solar cell based on dye-sensitized colloidal TiO2 films. Nature 353, 737-740 (1991)
3. M. Gratzel, Photoelectrochemical cells. Nature 414, 338 (2001)

4. T. Shiyani, T. Bagchi, Hybrid nanostructures for solar energy conversion applications. Nanomater. Energy 9(1), 1-8 (2020)

5. P.P. Ortega, C.C. Silva, M.A. Ramirez, G. Biasotto, C.R. Foschini, A.Z. Simoes, Multifunctional environmental applications of $\mathrm{ZnO}$ nanostructures synthesized by the microwaveassisted hydrothermal technique. Appl. Surf. Sci. 542, 148723 (2021)

6. J.S. Wu, D.F. Xue, Progress of Science and Technology of $\mathrm{ZnO}$ as Advanced Material. Sci. Adv. Mater. 3(2), 127-149 (2011)

7. S. Ghosh, A. Mallick, B. Dou, F.A.M. Van Hest Maikel, S.M. Garner, D. Basak, A novel blanket annealing process to achieve highly transparent and conducting $\mathrm{Al}$ doped $\mathrm{ZnO}$ thin films Its mechanism and application in perovskite solar cells. Sol. Energy 174, 815-825 (2020)

8. S. Paul, P.G. Harris, C. Pal, A.K. Sharma, A.K. Ray, Low cost zinc oxide for memristors with high On-Off ratios. Mater. Lett. 130, 40-42 (2014)

9. P.C. Asapur, T. Shiyani, S.K. Mahapatra, K.A. Bogle, I. Banerjee, Photo-electrochemical property of microwave synthesized muga silk nanoparticles/ZnO/ITO/PET Structure IETE Tech. Rev. (2020). https://doi.org/10.1080/02564602. 2020.1852121

10. T. Shiyani, S.K. Mahapatra, I. Banerjee, Basil sensitized ZnO photoelectrochemical cell for solar energy conversion. Mater. Today 32(3), 412-416 (2020)

11. L. Ghorbani, S. Nasirian, Zinc oxide nanorods assisted by polyaniline network as a flexible self-powered Ultraviolet photodetector: a comprehensive study. Appl. Surf. Sci. 527, 146786 (2020)

12. T. Shiyani, S. Agrawal, I. Banerjee, Natural dye sensitized photo electrochemical cells for solar energy conversion. Nanomaterials and Energy 9(2), 1-9 (2020)

13. T. Shiyani, S. K. Mahapatra, and I. Banerjee, Natural basil as photosensitizer with $\mathrm{ZnO}$ thin films for solar cell applications, IETE Journal of Research, pp. 1-8 (2020). Doi: https://doi. org/10.1080/03772063.2020.1768161.

14. E. Muchuweni, T.S. Sathiaraj, H. Nyakotyo, Synthesis and characterization of zinc oxide thin films for optoelectronic applications. Heliyon 3(4), e00285 (2017) 
15. S. Choudary et al., International journal of modern physics: conference series. World Scientific Publishing Company 22, 545-551 (2013). https://doi.org/10.1142/ S2010194513010647

16. W. Wang, T. Ai, Yu. Qi, Electrical and photocatalytic properties of boron-doped $\mathrm{ZnO}$ nanostructure grown on PET-ITO flexible substrates by hydrothermal method. Sci. Rep. 7, 42615 (2017)

17. M. Gupta, V. Sharma, J. Shrivastava, A. Solanki, Preparation and characterization of nanostructured $\mathrm{ZnO}$ thin films for photoelectrochemical splitting of water. Bull. Mater. Sci. 32(1), 23-30 (2009)

18. M. Caglar, Y. Caglar, S. Ilican, The determination of the thickness and optical constants of the $\mathrm{ZnO}$ crystalline thin film by using envelope method. J. Optoelectron. Adv. Mater. 8(4), 1410-1413 (2006)

19. H.E. Ali, V. Ganesh, L. Haritha, A.M. Aboraia, H.H. Hegazy, V. Butova, A.V. Soldatov, H. Algarni, A. Guda, H.Y. Zahran, Kramers-Kronig analysis of the optical linearity and nonlinearity of nanostructured Ga-doped $\mathrm{ZnO}$ thin films. Opt. Laser Technol. 135, 106691 (2021)
20. S. Asha, Y. Sangappa, S. Ganesh, Tuning the Refractive Index and Optical Band Gap of Silk Fibroin Films by Electron Irradiation. J. Spectroscopy 2015, 1-7 (2015)

21. F. Urbach, The long-wavelength edge of photographic sensitivity and of the electronic absorption of solids. Phys. Rev. 92, 1324 (1953)

22. E. Przezdziecka, K.M. Paradowska, A. Lysak, A. Wierzbicka, P. Sybilski, E. Placzek-Popko, R. Jakiela, J.M. Sajkowski, A. Kozanecki, Influence of As doping on the properties of nonpolar ZnO. Thin Solid Films 720, 138520 (2021)

23. N. Wang, D.Y. Jiang, Light trapping in $\mathrm{ZnO}$ nanowires to control ultraviolet photodetection responsivity. J. Mater. Sci. 56(9), 5708-5716 (2021)

24. R. Dom, S. Govindarajan, S.V. Joshi, P.H. Borse, A solarresponsive zinc oxide photoanode for solar-photon-harvester photoelectrochemical (PEC) cells. Nanoscale Adv. 2, 3350 (2020)

Publisher's Note Springer Nature remains neutral with regard to jurisdictional claims in published maps and institutional affiliations. 